\title{
Evaluation of an intervention to help students avoid unintentional plagiarism by improving their authorial identity
}

\author{
James Elander ${ }^{\mathrm{a}^{*}}$, Gail Pittam ${ }^{\mathrm{b}}$, Joanne Lusher ${ }^{\mathrm{c}}$, Pauline Fox ${ }^{\mathrm{d}}$ \& Nicola Payne
}

a. Centre for Psychological Research, University of Derby, UK

b. Faculty of Health and Social Care, Anglia Ruskin University, UK

c. Department of Psychology, London Metropolitan University, UK

d. Department of Psychology, Thames Valley University, London, UK

e. Department of Psychology, Middlesex University, London, UK

Correspondence: J.Elander@derby.ac.uk

Cite as:

Elander, J., Pittam, G., Lusher, J., Fox, P., \& Payne, N. (2010). Evaluation of an intervention to help students avoid unintentional plagiarism by improving their authorial identity. Assessment \& Evaluation in Higher Education, 23(2), 157-171.

\begin{abstract}
Students with poorly developed authorial identity may be at risk of unintentional plagiarism. An instructional intervention designed specifically to improve authorial identity was delivered to 364 psychology students at three post-1992 universities in London, UK, and evaluated with before-andafter measures of beliefs and attitudes about academic authorship, using the Student Authorship Questionnaire (Pittam et al., in press). Changes in questionnaire scores showed that the intervention led to significantly increased confidence in writing, understanding of authorship, knowledge to avoid plagiarism, and top-down approaches to writing, and significantly decreased bottom-up and pragmatic approaches to writing. For understanding of authorship, knowledge to avoid plagiarism, and pragmatic approaches to writing, significant intervention by year of study interaction effects showed that the greatest improvements were among year one undergraduates. Direct evaluative feedback showed that $86 \%$ of students believed the intervention helped them avoid plagiarism and $66 \%$ believed it helped them write better assignments. Post-intervention focus groups revealed changed student understandings about authorial identity and academic writing. The results show that interventions can help students avoid unintentional plagiarism by adopting more authorial roles in their academic writing. Further research could explore other influences on authorial identity, and examine the impact of authorial identity interventions on other outcome indicators.
\end{abstract}

Keywords: Authorship; authorial identity; plagiarism; academic literacy; writing.

\section{Introduction}

Student plagiarism is a considerable challenge for universities. In one UK study, $46 \%$ of undergraduates reported having copied an entire paragraph into their work without acknowledgement at least once, and $23 \%$ reported having done so more than once or twice (Bennett, 2005). In another study $57 \%$ of students had paraphrased without references and $53 \%$ had copied without references (Franklyn-Stokes \& Newstead, 1995). 
Part of the difficulty for institutions is that the term plagiarism includes a range of different behaviours, from buying or copying whole papers and submitting them as one's own, to less serious behaviours such as copying sections of material but leaving out quotation marks, or paraphrasing without appropriate acknowledgement (Park, 2003, summarises different forms of plagiarism). Students interviewed in one qualitative study had strong views about cheating and plagiarism, but their views were mixed and did not all align with the conventional perspectives of academic staff or institutions. Plagiarism was viewed generally as a less serious form of cheating, and there was much confusion about what practices constituted plagiarism and what students could do to avoid it (Ashworth et al., 1997).

Institutional procedures for plagiarism are often cumbersome, and dealing with plagiarism is often an unpleasant and difficult task for academics. It is good practice for students to be instructed at the beginning of each course about what plagiarism is, why it is undesirable, and what the institutional rules and practices are (Culwin, 2006), but to prevent plagiarism more effectively, institutions must go further than providing that kind of basic information. Plagiarism prevention programmes have taken three broad forms: systematic detection methods using software like Turnitin, honour codes to promote ethical values and standards, and instructional initiatives to improve student writing skills.

Approaches based on detection have a number of limitations and may not necessarily change student behaviour in the ways intended. Warn (2006), for example, suggested that 'cut and paste' approaches to essay writing would continue and that students would make greater use of paraphrasing to avoid detection. Honour codes aim to promote and maintain a culture of academic integrity, increase trust between students and staff, and foster a sense of appreciation and privilege among students. They involve clear communication of rules and standards, and moral socialisation of community members, sometimes including instruction in ethics. A series of large-scale US surveys showed that levels of cheating and academic dishonesty, including plagiarism, were significantly lower in institutions that operated honour codes than in those that did not (McCabe \& Bowers, 1994; McCabe \& Treviño, 2002; McCabe et al., 2001).

Detection approaches and honour codes focus mainly on motivational factors, but there is increasing evidence that many instances of the most common forms of plagiarism are unintentional, occurring, for example, 'when a student fails to adopt (perhaps because they do not know) proper protocols for referring to academic material, including appropriate ways of quoting, acknowledging ideas and compiling reference lists' (Park, 2003, p. 476). Valentine (2006) argued that treating plagiarism as a matter of honesty, locating it in a discourse of ethics, and judging it solely by reference to the submitted text can impede the development of appropriate academic writing skills: 'Students' opportunities to practice citation and the performance of honesty are closed down when their improper citation is read as a sign of dishonesty, rather than as a sign of an authentic beginner engaged in the work of acquiring a new discourse' (Valentine, 2006, p. 97). There have been calls for a more holistic approach to plagiarism that acknowledges that not all students are adequately prepared for higher education, and that makes efforts to develop students' academic skills (Macdonald \& Carroll, 2006).

Studies of student understandings of what is required in academic writing provide insights into potential unintentional plagiarism. A comparative qualitative study, for example, found that whereas tutors interpreted the assessment criteria for written assignments in terms of students' active cognitive engagement with sources and material, students understood them in terms of finding and placing material in their essays (Harrington et al., 2006). 
There is evidence that students have difficulty differentiating between paraphrasing and plagiarism (Roig, 1997) and often make plagiarising errors when asked to paraphrase complex, unfamiliar text (Roig, 1999), so several interventions have focused on paraphrasing and citation. Landau et al. (2002) found that paraphrasing exercises improved students' knowledge of plagiarism and their ability to paraphrase without plagiarising. Schuetze (2004) found that brief homework assignments on citation reduced students' citation problems and increased their confidence in being able to avoid plagiarism, and Barry (2006) found that practice with paraphrasing and citing original sources improved students' understanding of plagiarism. Homewood (2007) found that paraphrasing exercises and practice with citation reduced minor plagiarism (defined as $10-24 \%$ plagiarised content), although the lower incidence of serious plagiarism (more than $25 \%$ plagiarised content) remained stable.

Interventions like that may help students to avoid writing errors that could lead to unintentional plagiarism, but this approach is limited because paraphrasing is ultimately not the most desirable approach to academic writing. Greater paraphrasing skills may also enable students who intend to cheat to avoid detection (Warn, 2006).

Authorial identity is the sense a writer has of themselves as an author and the textual identity they construct in their writing. The concept of authorial identity was developed from analyses linking academic literacy and textual identity construction, which suggested that much unintentional plagiarism could occur because of 'students' failure to represent themselves as writers who should make a novel contribution, however modest it might be, through critically engaging with sources' (Abasi et al., 2006, p. 114). If poorly developed authorial identity is an important cause of unintentional plagiarism, then plagiarism countermeasures should include instructional interventions that target how students see themselves as writers, as well as technical aspects of writing such as paraphrasing and citation.

Interviews with students about authorship and authorial identity showed that they tended not to identify spontaneously with the role of author, and perceived an authorial approach to writing as likely to lead to lower marks being awarded (Pittam et al., in press), so there may well be scope for specific initiatives to promote and improve authorial identity among students.

This paper presents the evaluation of an intervention specifically designed to help students avoid unintentional plagiarism by improving their authorial identity. The intervention aimed to encourage students to see themselves as authors in their academic writing, and help them understand what being an author involves in positive terms, rather than focusing on practices associated with plagiarism that they should avoid, or on narrow writing skills such as paraphrasing. Materials were prepared to support student learning about the concept of authorship and the 'authorial decisions' that student writers must take to qualify as the genuine authors of their written work. Advice and instruction about authorship, writing and the avoidance of plagiarism was linked with discussion of high profile cases from within and outside academia. The intervention was delivered in different forms, at three institutions, by several different members of staff. It was integrated into existing modules, adapted for large and small groups of students and for modules with different forms of assessment, and delivered 2-4 weeks before assignment submission. A summary of the intervention is given in appendix 1.

\section{Methods}

The evaluation included before-and-after measures of students' beliefs and attitudes about authorship, using the Student Authorship Questionnaire (Pittam et al., in press). Student responses 
to the intervention were also assessed using a brief evaluation questionnaire and focus groups. Academic staff at the participating institutions completed a brief survey before and after the intervention about their perceptions of student plagiarism, and assessment board data was collected at one university on the numbers of students suspected of plagiarism or referred to disciplinary panels because of plagiarism.

\section{Participants and procedure}

The intervention was delivered to 364 undergraduate and postgraduate psychology students as part of timetabled classes at three large post-1992 universities in London, UK, all with diverse student populations. The Student Authorship Questionnaire (SAQ) was administered before and after students received the intervention. Almost all students present returned completed questionnaires, resulting in a participation rate in excess of $90 \%$. The questionnaire was anonymous and age and gender were not recorded. The before-and-after analysis is restricted to the 279 cases $(77 \%$ of the total) with complete before and after data for every SAQ item. There were 61 students (22\%) at University One, 175 (63\%) at University Two, and 43 (15\%) at University Three. There were 111 (40\%) year one undergraduates, 71 (25\%) year two undergraduates, 75 (27\%) year three undergraduates, and $22(8 \%)$ taught Masters (MSc) students.

Evaluation questions were distributed at the end of the session in which the intervention was delivered and were completed by 340 students. The invitation to take part in a focus group was made to all students at the beginning of the session, and 19 students subsequently took part in focus groups, comprising five students at University One (one from year one, four from year two), six students at University Two (five from year two, one from year three), and eight students at University Three (two from year three, six MSc students). In the staff survey, 32 academic tutors participated pre-intervention and 10 participated post-intervention.

Ethical approval for the study was obtained from the Faculty Research Ethics Committee at University One, and the study protocol was also considered and approved by the Psychology Department Ethics Committee at University Three, at the Department's request.

\section{Data collection}

The Student Authorship Questionnaire (SAQ) is an 18-item questionnaire measuring beliefs and attitudes to authorship and writing. It was designed to provide an alternative to metric-type measures used previously to assess risk of plagiarism (eg Landau et al., 2002), and writing process questionnaires focusing on the composition process itself (eg Lavelle, 1993; Torrance et al., 2000). The SAQ comprises 17 statements with five-point Likert-type response scales ranging from 'strongly agree' to 'strongly disagree', and one item that asks participants to indicate the proportion of their assignments they would expect to consist of quotations or material taken directly from other sources. The SAQ gives scores on six scales:

1. Confidence in writing: five items (e.g. 'I enjoy writing in my own words') measuring the extent to which students know what it means to express an idea in their own words, enjoy doing so, and are confident about their writing.

2. Understanding authorship: two items (e.g. 'I know what the responsibilities of an author are') measuring the extent to which students understand what it means to be the author of a piece of written work.

3. Knowledge to avoid plagiarism: three items (e.g. 'I know how to show which parts of my assignment were not written by me') measuring the extent to which students know how to provide citations and references and are confident they will not be accused of plagiarism. 
4. Top-down approach to writing: two items (e.g. 'When writing an assignment I begin by thinking about what I want to say, and then look for evidence relating to that') measuring the extent to which students believe that writing is about making arguments based on their own thoughts.

5. Bottom-up approach to writing: two items (e.g. 'When writing an assignment I begin by looking for material I can include and then think about how I can put it together') measuring the extent to which students approach writing by first looking for material and then thinking about how to arrange it.

6. Pragmatic approach to writing: four items (e.g. 'I get better marks when I use more material taken directly from books, journals or the internet in my assignments') measuring the extent to which students use more secondary material to improve their grades or save time.

The full questionnaire and details of its development, factor structure and internal reliability are given elsewhere (Pittam et al., in press). Scale scores are computed as the sum of the scores for the items making up each scale, divided by the number of items. Certain items are reverse-scored so that higher scores for each scale represent greater propensity towards the approach to writing described by the scale. For scales 1 to 4 , higher scores are more authorial. For scales 5 and 6 , higher scores are less authorial.

After the intervention, students also completed a brief evaluation questionnaire with ratings scales and open format questions. A 5-point Likert-type scale labelled 'strongly agree' to 'strongly disagree' was provided for students to indicate their degree of agreement with four statements about the intervention: '... helped me to understand how to avoid plagiarism'; '... helped me to write better psychology assignments'; '... helped me to enjoy writing psychology assignments'; and '... saved me from having to ask for advice or support about writing psychology assignments'. The open format questions invited students to respond in their own words to four questions: 'What would you say to a student considering joining one of these sessions in the future?'; 'What was good about the sessions, or went well?'; 'What was poor about the sessions, or went badly?'; and 'What was missing from the sessions, or should have been included?'

In the focus groups, which were conducted to explore any student perceptions and responses not captured by the questionnaire, students were asked whether the intervention had changed their understanding of authorship and plagiarism, what they found helpful and unhelpful about the intervention, and how the intervention could be improved. The focus groups were audio-recorded and transcribed, and quotes from these and responses to the open format questions in the student evaluation questionnaire are provided to illustrate students' reactions to the intervention.

The staff survey was conducted before the intervention (asking about the previous academic year) and after (asking about the academic year in which the intervention was delivered). There were five questions: 'What proportion of students on your modules do you believe ...' '... used an unacceptable proportion of material taken directly from other sources?; '... had plagiarised large parts of their assignments?'; '... were referred for disciplinary action because of plagiarism?'; '... had little idea how to avoid plagiarism?'; '... were at risk of being accused of plagiarism?'

Assessment board records were reviewed at University One and a count made of the numbers of referrals to disciplinary panels for plagiarism, and coursework submissions where plagiarism was suspected or investigated, during the academic year in which the interventions were delivered and during the previous academic year. 


\section{Results}

\section{Quantitative evaluation}

Descriptive statistics for the subscales of the SAQ are given in table 1. Repeated measures analysis of variance was used to test the effects of the intervention, year of study, and the intervention by year of study interaction. Multivariate effects, where the six subscales are combined, were significant for the intervention (Wilks' Lambda=0.63, $\mathrm{F}=26.6, p<.001$ ), year of study (Wilks' Lambda=0.84, $\mathrm{F}=2.8$, $p<.001$ ), and intervention by year of study interaction (Wilks' Lambda $=0.88, \mathrm{~F}=2.00, p=.008$ ). Table 2 shows the results of the univariate analyses. The intervention had significant main effects for every scale. Year of study had significant main effects for confidence in writing, understanding authorship and knowledge to avoid plagiarism. The intervention by year of study interaction had significant effects for understanding authorship, knowledge to avoid plagiarism and pragmatic approach to writing.

Table 1: Mean (SD) Student Authorship Questionnaire scores before and after the intervention

\begin{tabular}{lll}
\hline & Before & After \\
\hline Confidence & $3.24(.59)$ & $3.37(.59)$ \\
Understanding & $3.67(.82)$ & $4.36(.66)$ \\
Knowledge & $3.74(.74)$ & $3.95(.67)$ \\
Top-down & $3.13(.80)$ & $3.50(.78)$ \\
Bottom-up & $3.32(.77)$ & $3.03(.80)$ \\
Pragmatic & $2.66(.60)$ & $2.30(.64)$ \\
\hline
\end{tabular}

Table 2. Results of analysis of variance (univariate $\mathrm{F}$ ratios)

\begin{tabular}{llll}
\hline & Intervention & Year of study & $\begin{array}{l}\text { Intervention } \mathrm{x} \\
\text { year of study }\end{array}$ \\
\hline Confidence & $15.67^{* * *}$ & $4.98^{* *}$ & 1.43 \\
Understanding & $105.01^{* * *}$ & $3.87^{*}$ & $4.87^{* *}$ \\
Knowledge & $9.99^{* *}$ & $8.00^{* * *}$ & $3.91^{* *}$ \\
Top-down & $43.53^{* * *}$ & 1.71 & 0.19 \\
Bottom-up & $29.82^{* * *}$ & 0.36 & 0.35 \\
Pragmatic & $57.26^{* * *}$ & 1.69 & $3.17^{*}$ \\
\hline
\end{tabular}

$* \mathrm{p}<.05 ;{ }^{* *} \mathrm{p}<.01 ; * * * \mathrm{p}<.001$

Fig1. Mean SAQ scores before and after the intervention

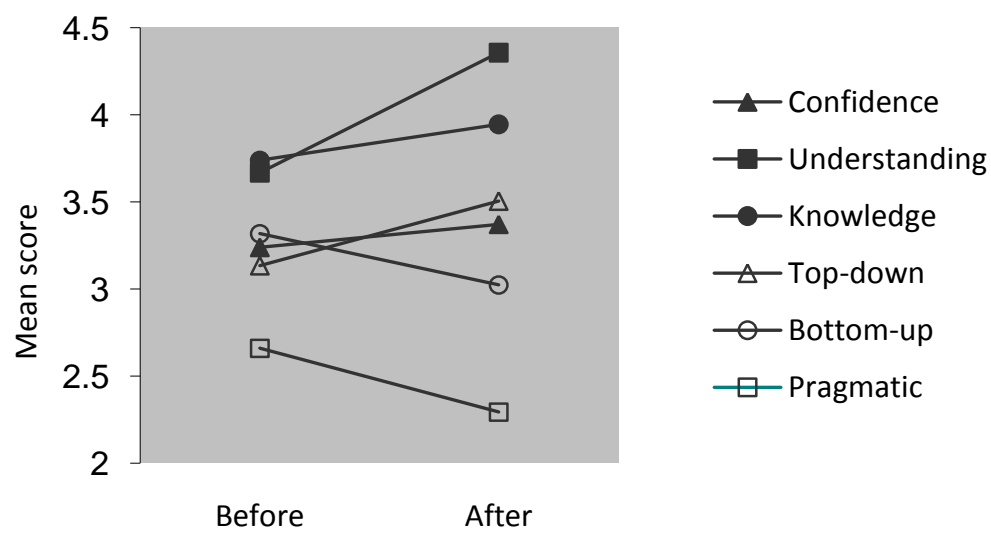

Scores were more authorial (higher for confidence, understanding, knowledge and top-down, and lower for pragmatic and bottom-up) for every scale after the intervention compared with before (fig 
1). The main effects of year of study were such that, for understanding authorship and knowledge to avoid plagiarism, scores were lowest for year one and highest for Masters Students, with years two and three intermediate. For confidence in writing, scores were higher for year two and Masters Students and lower for years one and three.

Fig 2a. Mean understanding authorship scores by year of study

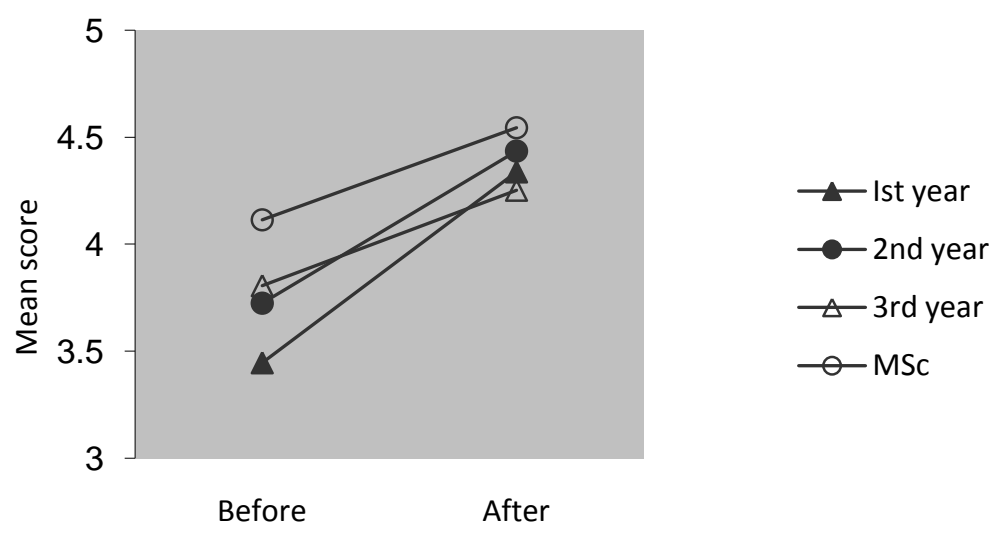

Fig 2b. Mean knowledge to avoid plagiarism scores by year of study

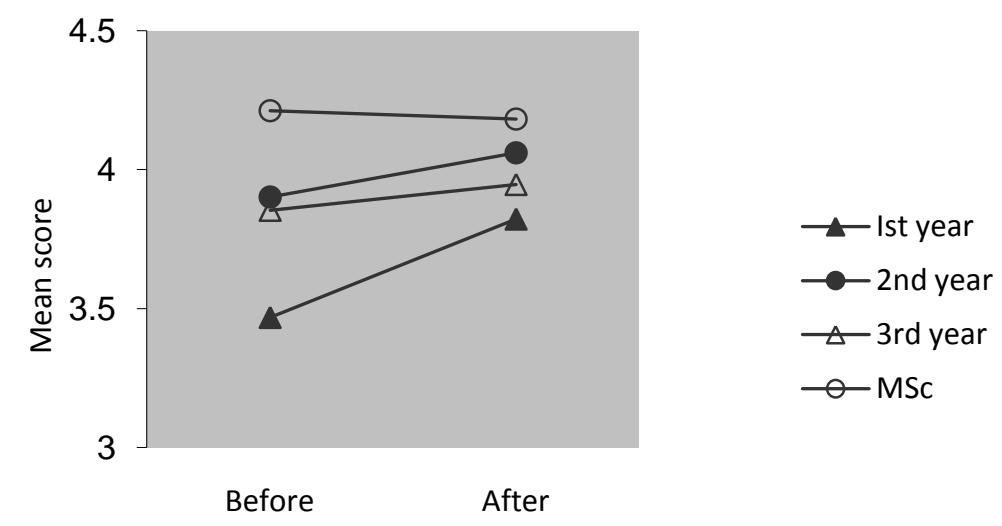

Fig 2c. Mean pragmatic approach to writing scores by year of study

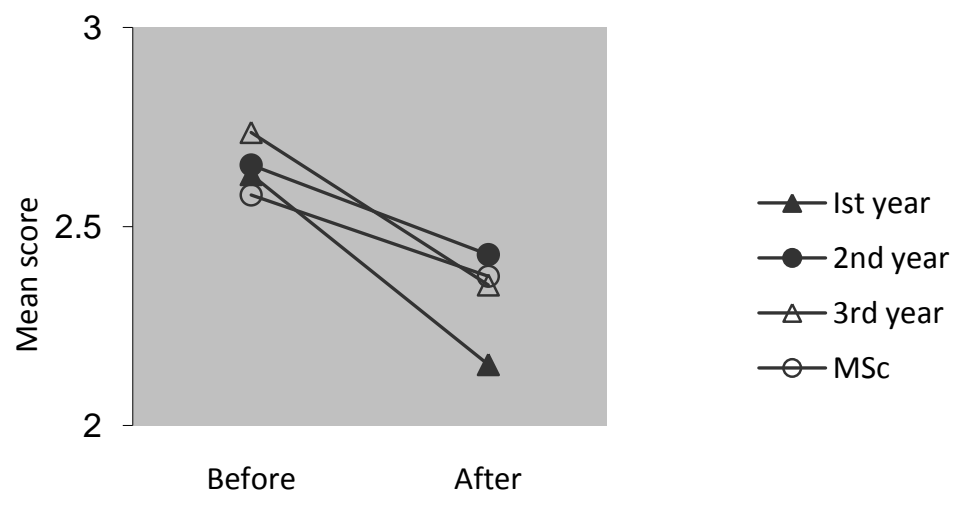


The significant interactions between intervention and year of study showed in each case that the impact of the intervention was greatest for year one students, with greater increases in understanding authorship and knowledge to avoid plagiarism, and greater decreases in pragmatic approach to plagiarism, among year one students compared with others (Fig 2).

The evaluation questionnaire was completed after the intervention by 340 students. The numbers who agreed or strongly agreed with the four statements showed that $86 \%$ believed the intervention helped them to avoid plagiarism, $66 \%$ believed it helped them to write better assignments, $40 \%$ believed it helped them to enjoy writing assignments, and $52 \%$ believed it saved them from having to ask for advice or support about writing assignments.

The results of the staff surveys are given in table 3. The changes in responses to all five items were in the direction of lower perceived incidence of behaviours associated with plagiarism following the intervention, but none of the before-after differences were statistically significant.

The data on disciplinary referrals and cases of suspected plagiarism recorded at assessment boards did not show a reduction. In fact the figures showed a small increase: there were 15 cases of suspected plagiarism during the previous year and 19 during the year of the intervention.

Table 3. Proportions of staff reporting that more than $20 \%$ of students on their modules were at risk of plagiarism before and after the intervention.

\begin{tabular}{llll}
\hline & Before & After & P* \\
\hline Q: What proportion of students on your modules ... & & & \\
... used an unacceptable proportion of material taken directly from other sources? & $19 \%$ & $0 \%$ & .17 \\
... do you believe had plagiarised large parts of their assignment? & $22 \%$ & $0 \%$ & .13 \\
... were referred for disciplinary action related to plagiarism? & $3 \%$ & $0 \%$ & .78 \\
$\ldots$ do you believe had little idea about how to avoid plagiarism? & $47 \%$ & $30 \%$ & .29 \\
... were at risk of being accused of plagiarism? & $31 \%$ & $30 \%$ & .63 \\
\hline
\end{tabular}

* Fisher's exact test

\section{Qualitative evaluation}

Responses to the open format questions in the student evaluation questionnaire indicated that the intervention was positively received by most students, for there were many more positive than negative comments. When asked what they would say to a student considering attending one of these sessions in the future, approximately $90 \%$ of the 307 students who responded to this question gave a positive response and indicated that they would advise other students to attend. This positive reception was echoed by the comments made by students in the focus groups.

Qualitative responses recorded in both the questionnaire and focus groups regarding what was good or helpful about the intervention are summarised below under the headings 'memorable aspects of the intervention' and 'changes to students' understanding and practice after the intervention'. Comments relating to what was poor, unhelpful or missing from the intervention, and how it could be improved, are summarised under the heading 'areas of continued confusion and suggested improvements to the intervention'. These categories are discussed further with the assistance of illustrative quotes.

\section{Memorable aspects of the intervention}

One focus group participant commented that although students already knew what plagiarism was, the intervention and the examples given were more interesting than past experiences of just being 
told what plagiarism is and not to do it, and others commented that the intervention was a useful reminder to help students avoid making common mistakes. The following comments were also made by students on the evaluation questionnaire:

'At first I did not realise that I was also an author if I use my own words within my essay' (Year one student)

'I thought I knew a lot about authorship but realised there is much more to it' (Year three student)

Other comments made by students on the evaluation questionnaire included: 'simple but effective' from a year one student, 'useful tips on how to enjoy and take responsibility for your writing' and 'clear examples on how easy it is to plagiarise' by year three students.

The examples of writing provided during the intervention were well received by many students. One student commented in the evaluation questionnaire:

'Examples of pieces of work helped to illustrate what is meant by the generic rules students are given about plagiarism' (Year three student)

The examples of high profile cases of plagiarism made an impression on some students in the focus groups:

'The psychologist who had just changed a few words, I know in the past I've done that, oh it's not the exact same so it's still mine' (Year two student)

'It was quite interesting seeing the number of professionals, it was quite shocking because I always just think of it at student level, I never think that anyone would dare to go through so much hard work and then ...' (Year two student)

Changes to students' understanding and practice after the intervention

Questionnaire responses suggested that the intervention had an impact on students' awareness and confidence, and made them think again about their writing:

'Made me a bit confident on doing my essay in terms of referencing and quotation' (Year one student)

'It gave me a bit of confidence, that is by making me think again about how I'm going to write my next essay and maybe practising how to write more' (Year one student)

'It will inspire you to think more originally about your approach towards your written work' (Year two student)

Several focus group participants described how what they learnt during the intervention would have an impact on how they approach written assignments in the future:

'I think that we would take a lot more care in how we present our work and what things we do put in and look at it very much more in a broader view' (Year one student)

'I like the way that you were encouraged to think about what you were going to say, which for some reason hadn't really dawned on me ... so you are really in the driving seat, and then take from sources to support your own perspective. So you've got a standpoint right from the start ... 
I think what I've done before is almost highjack someone else's drive and just go through whatever, conclude it their way' (Year three student)

Many student focus group responses were positive about adopting more authorial roles in academic writing:

'I know one thing that I did get from that session was the need to make sure that you really did put your own ideas in and move research on ... I actually did come away with a much greater sense that you really should move things on a bit and not be afraid to put more of your ideas and understanding about where you think research is heading or any other sort of ideas' (Year three student)

There were also indications from the focus groups that a greater sense of authorial identity was associated with a better understanding of writing in the discipline and with attributes of deep learning such as critical analysis:

'It opens your mind up about how you should approach psychology and how you should write psychological pieces of work from the beginning' (Year one student)

'I think you do, you'll look at it in more in a positive light, when you're looking at your work, you'll look at it in a more critical analytical view, like how you're going to put this together' (Year two student)

Areas of continued confusion and suggested improvements to the intervention

The few students who provided negative evaluations in the questionnaire thought the intervention was too long, too repetitive, too boring, too academic, too much like common sense, or felt they had not learnt anything new. Several students commented on the timing of the intervention, suggesting either that it should take place right at the beginning of the degree programme (a year one student), or was more suitable for year one students (year three and Masters students), or would be better mid-way through year three, when students have some experience and are better able to put it into context (year two and three students). Several students would have liked the intervention further in advance of module assignments.

Some students commented in the questionnaire that they would have liked more information on aspects including analysis, critical writing, putting academic concepts in their own words, using quotes, or referencing. Others would have liked more information about authorship in the context of group work, about lecturers' impressions of students' work, or about internet plagiarism. Other requests were for more interactive content and more examples of students' work. Comments made in the focus groups included:

'I think it's better to give some practice exercise rather than just giving examples and how to deal with them' (Year three student)

'The examples that you gave were so obvious that they were plagiarism. I want to know about borderline cases' (MSc student)

A few students reported in the questionnaire that they felt more nervous or self-conscious about essay writing after the intervention, and two focus group participants (year two and year three students) expressed continuing confusion about the extent to which they should put their own ideas in their work and back points up with references. Some focus group participants whose first language was not English would have liked more advice about common mistakes made by international students. 


\section{Discussion}

The results show that interventions focusing on authorial identity can be used to help students avoid unintentional plagiarism by adopting more authorial roles in their academic writing. The intervention led to significant improvements in each of the scales of the questionnaire, meaning increased confidence in writing, understanding of authorship, knowledge to avoid plagiarism, and top-down approaches to writing, and less bottom-up and pragmatic approaches to writing. The changes were greatest for year one students, supporting the common sense case for providing instruction in the avoidance of plagiarism as early as possible in students' university careers.

Direct evaluative feedback was also positive, with $86 \%$ of students reporting they believed the intervention helped them to avoid plagiarism, and $66 \%$ reporting they believed it helped them to write better assignments. It could be argued that the post-intervention evaluation questionnaire constituted an implicit prompt (students were asked to indicate their agreement/disagreement with positive statements about the intervention). However, the students were explicitly prompted to make negative evaluations in the open-format questions, and the focus groups provided opportunities for comment and discussion about weaknesses and limitations of the intervention.

The improvements in beliefs and attitudes about authorship and writing did not, however, translate into significant reductions in staff perceptions of student writing behaviours, or reductions in the numbers of students suspected of plagiarism or referred for disciplinary measures associated with plagiarism. However, the changes in staff perceptions were in the expected direction, and the numbers of staff participants in the follow-up survey (which had to take place after the end of scheduled teaching and assessment) were much smaller than those prior to the intervention, which reduced the power to detect changes. It is also possible that the presence of the project may have sensitised staff to student plagiarism, leading to smaller reductions than otherwise in staff perceptions of student behaviours.

There are a number of possible reasons for the absence of a reduction in recorded cases of students suspected or referred for disciplinary action for plagiarism. First, in the very small minority of cases where disciplinary action is considered because of plagiarism, the forms of plagiarism involved are usually more serious and more intentional than those addressed by the intervention. A previous intervention targeting paraphrasing, for example, reduced the incidence of frequent, minor forms of plagiarism, but not more serious forms (Homewood, 2007). Second, the existence of the intervention may have heightened staff awareness of plagiarism in the participating departments, leading to greater vigilance and more reporting of plagiarism during the year of the intervention. Third, more time, with sustained programmes of instruction and intervention, may be required to translate changes in beliefs and attitudes into changes in behaviours and performance that would be measurable by official records.

The intervention aimed to change students' views of themselves as academic writers, and promote approaches to writing associated with genuine authorship. This orientation differentiates it from previous skills-based interventions focusing on citation methods or paraphrasing exercises (e.g. Barry, 2006; Landau, 2002; Schuetze, 2004). Previous analyses have identified authorial identity construction as important in understanding and preventing plagiarism (Abasi et al., 2006), but this is the first evidence to our knowledge that brief, flexible interventions can improve students' beliefs and attitudes about themselves as authors, at least in the short term.

The Student Authorship Questionnaire measures beliefs and attitudes about authorship and writing, rather than plagiarism per se. The top-down, bottom-up and pragmatic scales focus on approaches to writing, the top-down approach being characterised by working from concepts and ideas rather 
than source material, and the bottom-up approach being characterised by the reverse strategy. The pragmatic scale measures a strategic approach to writing characterised by adopting strategies to save time or maximise marks. Those approaches to writing may be related to deep, surface and strategic approaches to learning (Entwistle et al., 2000) and there was some evidence from student responses that focusing on approaches to academic writing may help to promote deeper approaches to learning.

Further research with outcome measures of student writing performance would be worthwhile, including analyses of changes in grade achievement following interventions, or analyses of the content of submitted student assignments, using software to estimate the proportion of plagiarised content or content analyses to assess genuine authorial content. Further research could also examine differences between groups of students, for example between those with different study histories or from different learning cultures. In order to achieve the most inclusive participation possible, and because of the sensitivity of the subject of plagiarism, in the present study we recorded no demographic or other characteristics that could be perceived as capable of being used to identify students, but in other contexts it may be useful to examine age and gender differences, compare home versus international students, and explore disciplinary differences. The present focus was on psychology, but the approach could easily be adapted for other disciplines where students produce written assignments, and the intervention and evaluation materials are available on request for practitioners or researchers wishing to adapt, deliver and evaluate the intervention in other settings.

\section{Acknowledgements}

The project was funded by a Higher Education Academy Psychology Network Departmental Teaching Enhancement Scheme grant awarded to James Elander. Many thanks to all the students who participated in the intervention and evaluation; to Kathryn Mitchell for helping to administer the project at University One; to Meme Pang for helping with the collection of assessment board data, to Katherine Harrington and Frank Su of the Write Now CETL for support and liaison with the CETL; and to a reviewer for helpful comments on an earlier draft.

\section{References}

Abasi, A.R., Akbari, N. \& Graves, B. (2006). Discourse appropriation, construction of identities, and the complex issue of plagiarism: ESL students writing in graduate school. Journal of Second Language Writing, 15 (2), 102-117.

Ashworth, P., Bannister, P. \& Thorne, P. (1997). Guilty in whose eyes? University students' perceptions of cheating and plagiarism in academic work and assessment. Studies in Higher Education, 22, 187203.

Barry, E.S. (2006). Can paraphrasing practice help students define plagiarism? College Student Journal, 40 (2), 377-385.

Bennett, R. (2005). Factors associated with student plagiarism in a post-1992 university. Assessment and Evaluation in Higher Education, 30, 137-162.

Culwin, $F$ (2006). An active introduction to academic misconduct and the measured demographics of plagiarism. Assessment and Evaluation in Higher Education, 31, 167-182.

Entwistle, N., Tait, H. \& McCune, V. (2000). Patterns of response to an approaches to studying inventory across contrasting groups and contexts. European Journal of Psychology of Education, 15, 33-48.

Franklyn-Stokes, A. \& Newstead, S. (1995). Undergraduate cheating: who does what and why? Studies in Higher Education, 20, 159-172. 
Harrington, K., Elander, J., Norton, L., Reddy, P., Aiyegbayo, O. \& Pitt, E. (2006). A qualitative analysis of staff-student differences in understandings of assessment criteria. In C. Rust (Ed.), Improving Student Learning Through Assessment (pp. 235-247). Oxford: Oxford Centre for Staff and Learning Development.

Homewood, J. (2007). An active approach to preventing plagiarism and increasing generic skills in new undergraduate students: the PSY104 project. Paper presented at the Higher Education Academy Conference, 3-5 July 2007, Harrowgate, UK.

Landau, J.D., Druen, P.B. \& Arcuri, J.A. (2002). Methods for helping students avoid plagiarism. Teaching of Psychology, 29 (2), 112-115.

Lavelle, E. (1993). Development and validation of an inventory to assess processes in college composition. British Journal of Educational Psychology, 63, 489-499.

Macdonald, R. \& Carroll, J. (2006). Plagiarism - a complex issue requiring a holistic institutional response. Assessment and Evaluation in Higher Education, 31, 233-245.

McCabe, D.L. \& Bowers, W.J. (1994). Academic dishonesty among males in college: a thirty year perspective. Journal of College Student Development, 35, 5-10.

McCabe, D.L. \& Treviño, L.K. (2002). Honesty and honor codes. Academe, 88, 37-42.

McCabe, D. L., Treviño, L. K. \& Butterfield, K. D. (2001). Cheating in academic institutions: A decade of research. Ethics and Behavior, 11, 219-32.

Park, C. (2003). In other (people's) words: plagiarism by university students--literature and lessons. Assessment and Evaluation in Higher Education, 28, 471-488.

Pittam, G., Elander, J., Lusher, J., Fox, P. \& Payne, N (in press). Student beliefs and attitudes about authorial identity in academic writing. Studies in Higher Education.

Roig, M. (1997). Can undergraduate students determine whether text has been plagiarised? Psychological Record, 47, 113-122.

Roig, M. (1999). When college students' attempts at paraphrasing become instances of potential plagiarism. Psychological Reports, 84, 973-982.

Schuetze, P. (2004). Evaluation of a brief homework assignment designed to reduce citation problems. Teaching of Psychology, 31 (4), 257-259.

Torrance, M., Thomas, G.V. \& Robinson, E.J. (2000). Individual differences in undergraduate essay-writing strategies: A longitudinal study. Higher Education, 39, 181-200.

Valentine, K. (2006). Plagiarism as literacy practice: recognising and rethinking ethical binaries. College Composition and Communication, 58, 89-109.

Warn, J. (2006). Plagiarism software: no magic bullet! Higher Education Research and Development, 25, 195-208. 
Appendix 1: Summary of the intervention

Part 1: Definitions of author and authorship are given that emphasise that an author must add to what existed previously and that authorship assigns both credit and responsibility for the work. The special role of the student author, who must produce an original piece of work while necessarily drawing heavily on other sources, while still inexpert in the topic, and usually under time pressure, is acknowledged.

Part 2: The concept of 'authorial decisions' is introduced as a way of operationalising what an author must do to take responsibility for writing that includes material from other sources. These are decisions about:

- What the message is

- What secondary material to use

- How much importance or emphasis to put on different parts

- How to interpret the material

- What words to use to express the ideas

- What conclusions to reach

Examples of different styles (eg journalistic versus academic) of writing on the same topic are given to prompt discussion about what decisions the authors took that resulted in the writing they produced.

Part 3: Two examples of student writing are given to prompt discussion of the relative merits of each and the different roles adopted by the writers. Both include the same material from the same referenced sources, but one consists almost entirely of secondary material (the writer has acted more as an editor than an author), whereas in the other the writer has interpreted the material and made a series of points about it. The use of quotations is discussed, with extracts from interviews with students and tutors advising students to think carefully about quotations and be sure about what point is made by the quote, why it has been selected, and what the author can add by way of comment, evaluation or interpretation.

Part 4: High profile examples of suspected or alleged plagiarism are presented for discussion, along with the explanations given by the authors and the lessons to be drawn from the cases. These include:

- Novelist Dan Brown's court case over the book The Da Vinci Code (Brown was accused but exonerated of plagiarising a previous book, and the reasons given for his exoneration help to define the boundaries of authorship and plagiarism)

- The UK Labour Government's ‘Dodgy Dossier' on Iraq's supposed weapons of mass destruction, alongside extracts from the PhD thesis which the dossier closely resembled

- Psychiatrist Raj Persaud's article about research on obedience, alongside an almost identical extract from a previous paper by another author, and Persaud's explanation that the unintended similarity resulted from word processing and formatting errors in his writing

- A plagiarism expert who was accused of plagiarism in a report about plagiarism! Examination of these high profile cases shows that even professional writers and academics risk being accused of plagiarism if they do not take great care with the formatting and presentation of their writing.

Part 5: Discussion of authorship and plagiarism issues in relation to specific forms of assignment, including essays, case studies, critical reviews and research dissertations, and a pre-submission checklist for students to test whether they qualify as the author of the work they submit for assessment. 